\title{
AMENDMENTS
}

nature

structural \& molecular biology

\section{Author Correction: Structures of the TRPM5 channel elucidate mechanisms of activation and inhibition}

Zheng Ruan (D, Emery Haley, Ian J. Orozco, Mark Sabat, Richard Myers, Rebecca Roth, Juan Du (DD and Wei Lü (D)

Correction to: Nature Structural \& Molecular Biology https://doi.org/10.1038/s41594-021-00607-4, published online 24 June 2021.

In the version of this article initially published, the reference "Liu, D. \& Liman, E. R. Intracellular $\mathrm{Ca}^{2+}$ and the phospholipid PIP ${ }_{2}$ regulate the taste transduction ion channel TRPM5. Proc. Natl Acad. Sci. USA (2003)" was omitted. It should have been cited in the first paragraph of the Introduction after the phrase "TRPM5 is activated upon the elevation of cytoplasmic Ca ${ }^{2+}$ concentration..." as reference 3. Reference 12 in the original version of the article (Prawitt et al.) should also have been cited at this location, and it should have been reference 4 . The errors have been corrected in the HTML and PDF versions of the article.

Published online: 20 July 2021

https://doi.org/10.1038/s41594-021-00641-2

(C) The Author(s), under exclusive licence to Springer Nature America, Inc. 2021

\section{Author Correction: Cryo-EM structure of SARS-CoV-2 ORF3a in lipid nanodiscs}

David M. Kern (D), Ben Sorum, Sonali S. Mali, Christopher M. Hoel D, Savitha Sridharan, Jonathan P. Remis, Daniel B. Toso, Abhay Kotecha Diana M. Bautista and Stephen G. Brohawn (D)

Correction to: Nature Structural \& Molecular Biology https://doi.org/10.1038/s41594-021-00619-0, published online 22 June 2021.

In the version of this article initially published, in the first sentence of paragraph three in the Introduction, it was incorrectly stated that the SARS-CoV-2 genome encodes the viroporin ORF8a. The correct version of the sentence is " 3 a has been proposed to form an ion channel and is one of two putative viroporins encoded by the SARS-CoV-2 genome together with the envelope protein E (SARS-CoV-1 encodes an additional putative viroporin, ORF8a)." The error has been corrected in the HTML and PDF versions of the article.

Published online: 20 July 2021

https://doi.org/10.1038/s41594-021-00642-1

(๑) The Author(s), under exclusive licence to Springer Nature America, Inc. 2021 